\title{
Beauvaria bassiana keratitis
}

\author{
SETH W SACHS,' JULES BAUM,' AND CAROLYN MIES ${ }^{2}$ \\ From the Departments of 'Ophthalmology and ${ }^{2}$ Pathology, Tufts University School of Medicine and New \\ England Medical Center, USA
}

SUMMARY The cornea of a 64-year-old white male underwent progressive thinning following removal of a foreign body and after treatment with topical antibiotics and corticosteroid. Initial attempts at laboratory identification of an infectious agent were negative. The process progressed to corneal perforation. After a penetrating keratoplaty, histopathological examination of host button tissue showed a fungus, identified as Beauvaria bassiana on culture.

The incidence of fungal keratitis has increased in recent years. The fungal genus Beauvaria is an insect pathogen found in the soil. Interestingly, it holds a rather prominent place in historical microbiology, as it was the first organism shown to produce a disease. ${ }^{\prime}$ Only two cases of beauvaria infection in man have been reported. ${ }^{23}$ Although Lichaa ${ }^{4}$ and Langeron ${ }^{5}$ reported a case of keratoconjunctivitis caused by beauvaria, Langeron later reclassified the fungus into a different genus. ${ }^{6}$ In this report we present the first case of beauvaria keratitis.

\section{Case report}

A 64-year-old white male Massachusetts farmer was referred to the New England Medical Center Ophthalmology Service in November 1980. In June 1980 an asymptomatic 'spot' on his right eye was noted. In October 1980 he sustained a corneal abrasion in the right eye. A corneal foreign body described as 'vegetable matter' surrounded by a white stromal infiltrate was noted in addition to the abrasion. The foreign body was removed. Corneal scraping revealed 'polymorphonuclear leukocytes and no organisms' on Gram stain. Bacterial and fungal cultures had no growth. The patient was placed on gentamicin drops without a change in clinical appearance. He was then referred to the New England Medical Center's (NEMC) Corneal/ External Disease Service. On initial examination there the patient complained of mild photophobia

Correspondence to Jules Baum, MD; Department of Ophthalmology, New England Medical Center, 171 Harrison Avenue, Boston, MA 02111, USA. and had a foreign body sensation. Best corrected visual acuities were $6 / 12$ in the right eye and $6 / 6$ in the left eye. The conjunctiva of the right eye was $1+$ diffusely injected. A white inferior paracentral infiltrate without thinning was present on the cornea of the right eye. The anterior chamber of the right eye was without flare or cells. The initial impression was of an inflammatory keratitis secondary to a previous foreign body. Gentamicin drops were discontinued. Chloramphenicol-polymyxin-hydrocortisone ointment was begun three times daily and the patient was returned to the referring ophthalmologist.

After initial improvement the infiltrate increased in size. Chloramphenicol-polymyxin-hydrocortisone was stopped and gentamicin drops were restarted: The patient's discomfort worsened, conjunctival injection increased, and the corneal infiltrate increased in size. The gentamicin drops were stopped after several days and dexamethasone ointment four times daily was begun. The patient was again referred to the New England Medical Center. He had only a mild foreign body sensation.

Visual acuity on that date (8 January 1981) was $6 / 10$ in the right eye. The conjunctiva was normal. An infiltrate of approximately $4 \mathrm{~mm}$ was noted inferotemporal to the visual axis. The cornea was approximately $40 \%$ thinned at the superior aspect of the lesion. A dense stromal haze surrounded the region. The anterior chamber was normal. The stromal thinning was thought to be a secondary effect of the steroid, and an attempt to taper the drug was made. The patient returned one week later (15 January 1981), at which time no change was noted in his clinical appearance. Corneal scrapings for bacterial and fungal cultures were repeated. A corneal biopsy 
showed moderate stromal oedema and a few scattered neutrophils. Methanimine silver and Gram stains for fungi and bacteria were negative. Bacterial and fungal cultures were negative. The Patient was seen on 19 January 1981, at which time no change in the clinical picture could be detected. A soft contact lens was placed on the eye, and chloramphenicolpolymyxin-hydrocortisone ointment twice daily was reinstituted. The contact lens was removed by the referring ophthalmologist three days after insertion owing to 'iritis.' Atropine drops were added in addition to the chloramphenicol-polymyxin-hydrocortisone. The patient was seen by the referring ophthalmologist on 4 February 1981, when a corneal perforation was noted. He was referred back to New England Medical Center.

The perforation was initially sealed with isobutyl cyanoacrylate glue. The patient underwent a penetrating keratoplasty two days later. Histological sections of the cornea showed an infiltrate composed of necrotic debris, neutrophils, and mononuclear inflammatory cells at the perforation site. The adjacent stroma was oedematous and infiltrated by numerous acute and chronic inflammatory cells (Fig. 1). Occasional hyphae were seen in deep stroma and adjacent to Descemet's membrane. Cultures from the host button grew Beauvaria bassiana, a finding confirmed by both the Massachusetts and New York
State mycology laboratories. The organism produced a white cottony colony and was identified by its unique zigzag conidiophore, thickened at the base. So far the corneal transplant has remained clear, with best visual acuity of $6 / 13$ in the right eye.

\section{Discussion}

The genus Beauvaria comprises several common species of soil fungi that are pathogenic for insects. Interestingly, it holds a prominent place in historical microbiology. Bassi in 1835 demonstrated that beauvaria was the causative agent in producing the muscardine disease of silkworm. ' This was the first demonstration of a micro-organism producing a disease process. In culture beauvaria grows as a white or slightly pigmented, fluffy to powdery colony. Microscopically the hyphae are narrow. The sporebearing cells form single, irregularly grouped or radiating masses. A characteristic feature of this genus is the zigzag configuration which the sporebearing tip assumes.?

Beauvaria first came to the attention of medical mycologists in the 1930s. Lichaa in 1933 and Langeron in 1934 reported the same case of keratoconjunctivitis in a 17-year-old Egyptian girl. ${ }^{45}$ Langeron originally classified the fungus as Beauvaria brumptii. However, several years later

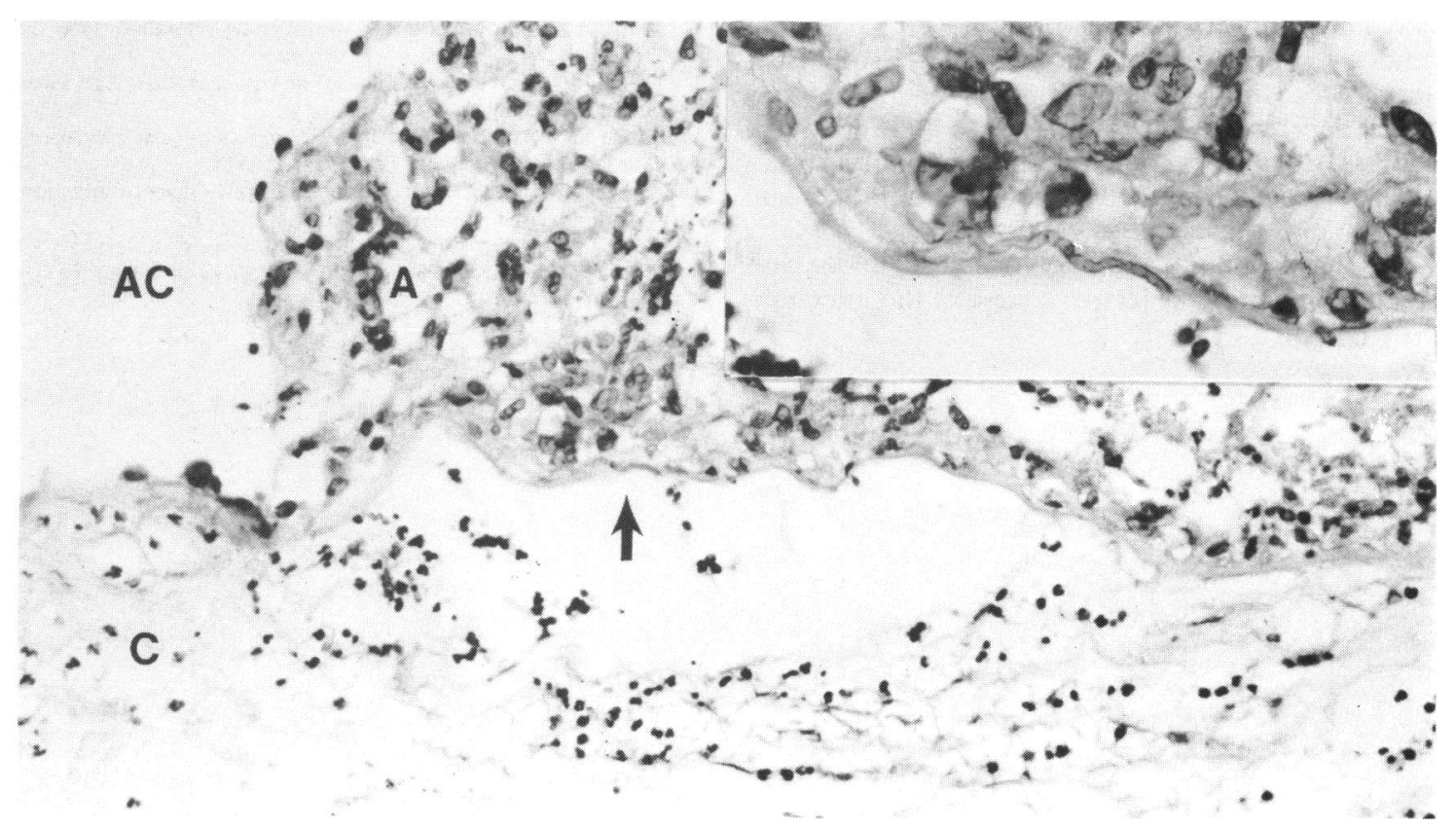

Fig. 1 Histological section of the cornea showing fungus at Descemet's membrane (arrow and inset). A=abscess; $\mathrm{AC}=$ anterior chamber $\mathrm{C}=$ cornea . (Haematoxylin and eosin, $\times 275$; inset, $\times 688$.) 
Langeron transferred it to the genus Tritirachium as $T$. brumptii. The case presented in this report represents the only reported instance of beauvaria producing ocular disease.

There are very few reports of beauvaria producing systemic disease in man. In 1966 Freour et al. reported a case of pulmonary disease in a 22 -year-old woman in whom $B$. bassiana was isolated from surgically excised lung tissue. ${ }^{2}$ In 1980 Drouhet $e t$ al. reported a case of osteoarthritis caused by beauvaria. ${ }^{3}$

Why did the fungus become pathogenic in our case? The history suggests that a corneal foreign body was present for several months and was very well tolerated. After its removal the corneal changes remained relatively unaltered on antibiotic drops. With both bacterial and fungal smears and cultures negative the patient was placed on a topical corticosteroid. After initial improvement the corneal process became more aggressive. Repeat cultures and corneal biopsy were negative for fungi. Corneal thinning progressed and eventually led to perforation.

Both antibiotics and steroids have been suspected of potentiating fungal infections of the eye. While antibiotic potentiation of oculomycoses has not been studied extensively, evidence has accumulated showing that some antibiotics may enhance fungal growth or potentiate fungual virulence. The investigation of corticosteroids has been more extensive. They not only enhance the virulence of pathogenic fungi but render saprophytic fungi pathogenic. Tissue resistance is also reduced by a number of mechanisms which depress the immune response and reparative processes. Numerous clinical and laboratory studies have been published on the effects of antibiotics and steroids in corneal and systemic processes $s^{\text {t-13 }}$

We suggest that the addition of steroid in our case resulted in a more aggresive course of the infection, leading to perforation. Although initial attempts at fungal identification and culture proved negative, as in the present case, one's index of suspicion must remain high when the clinical setting suggests a fungal infection.

We thank Morris Gordon, $\mathrm{PhD}$, for his expert advice and Norman Wald, MD, for referring the patient.

\section{References}

1 Bassi A. Del male del segno calcinaccio o muscordino malattia che attigee: Bachi da set a Patel. Teorica Tip. Orcesi, Lodi, 1835. In: Rippon JW. Medical mycology-the pathogenic fungi and the pathogenic actinomycetes. Philadelphia: Saunders, 1974: 467.

2 Freour P, Lahourcade M, Chomy P. Une mycose nouvelle: étude clinique et mycologique d'une localisation pulmonaire de 'Beauvaria.' Bull Mem Soc Med Hop Paris 1966; 117: 197-206.

3 Drouhet E, Dupont B, Dompmartin E, Heid E, Ravisse P. Ketoconazole, a new imidazole active by the oral route in the superficial and systemic mycoses. Bull Soc Fr Mycol Med 1980; 9: 53-7.

4 Lichaa M. Mycose oculaire primitive due au Beauvaria brumptii. Bull Ophthalmol Soc Egypt 1933; 26: 91-5.

5 Langeron M. Mycose oculaire primitive due au Beauvaria brumptii. Bull Acad Natl Med (Paris) 1934; 111: 133-7.

6 Langeron M. Tritirachium brumpti (Langeron and Lichaa 1934) Langeron 1947 et le genre Tritirachium Limber 1940. Ann Parasitol Hum Comp 1947; 22: 94-9.

7 Emmon C, Binford C, Utz J, Kwon-chung KJ. Medical mycology. 3rd ed. Philadelphia: Lea and Febiger, 1977: 523.

8 Frenkel JK. Role of corticosteroids as predisposing factors in fungal disease. Lab Invest 1962; 11: 1192-208.

9 Rheins MS, Suie T, Van Winkle MG, Havener W. Potentiation of mycotic ocular infections by drugs. Br J Ophthalmol 1966; 50: 533-9.

10 Zimmerman L. Ocular mycoses-mycotic keratitis. Lab Invest 1962; 11: 1151-60.

11 Mitsui $\mathrm{Y}$, Hanabusa J. Corneal infections after cortisone therapy. Br J Ophthalmol 1955; 39: 244-50.

12 Francois J, Rysselaere M. Factors which favor mycotic infections -oculomycoses. Springfield: Thomas, 1972: 35-43.

13 DeVoe AG, Silva-Hutner M. Fungal infections of the eye. In: Locatcher-Khorazo D, Seegal BC, eds. Microbiology of the eye. St Louis: Mosby, 1972: 208-40. 